\title{
ФИЛОСОФИЯ
}

УДК $301: 37$

DOI: $10.21779 / 2500-1930-2018-33-4-56-65$

\section{М.Р. Деметрадзе}

\section{Социокультурная методология разработки модернизационной политики}

Российский государственный гуманитарный университет; Россия, г.Москва, Миусская площзад,.6, стр. 1; demetradze1959@mail.ru

В статье предпринята попытка представить социокультурную методологию модернизационной политики, в которой стратегическую функцию выполняют такие категории, как социализация, заимствование и адаптация. Специфика и структура каждого из этих механизмов позволяет определить, в каких случаях модернизация приобретает инновационно-опережающий, инновационно-догоняющий или имитационно-подражательный вектор. Цели социокультурной методологии: опора на специально разработанную научно-теоретическую модель модернизации, привязка политики к интересам и запросам общества, ее направленность на поддержание и постоянное совершенствование условий жизни индивидов. Она закладывает фундамент профессионального и рационального управления государством. Тезисы «вся власть специалистам», «здоровая и образованная нация» подчиняются принципу «устойчивое и контролируемое развитие». Первичность человеческого фактора и человеческого потенциала, совершенствование условий жизни, изменение общества к лучшему - базис социокультурной модели модернизации.

Ключевые слова: сочиокультурная методология, сочиокультурная модернизащия, сочиализачия, заимствование, адаптачия, инновачионная стратегия, коммуникативные каналь, устойчивое и контролируемое развитие.

Изучение практических достижений различных стран мира является актуальной задачей обществ постсоветского пространства, для которых важен опыт создания современного государства и интеллектуального капитала, осуществления модернизационных преобразований.

Наша цель - предложить социокультурную методологию разработки модернизационной политики, которая позволяет выявить и обосновать ее различные типы.

Теорией модернизации в разных странах, а также типами революционных изменений занимались и занимаются многие исследователи, в частности: Альмонд [Almond G. and Powell G.B. 1966], Аптер [Apter D. 1987], Арон [Aron, 1969], Бейкер [Baker, 1990], Динер [Dinner, 1985], Эйзенштадт [Eisenstadt, 1987], Белл [Белл, 1999], Ростоу [Ростоу, 1973], Форрестер [Форрестер, 2006], Хобсббаум [Хобсббаум, 1999], Хиршман [Хиршман, 2010], Запф [Zapf, 1991], Тирьякян [Tiryakian, 1990], Инкелес и Смит [Inkeles and Smith, 1974], Лернер [Lerner, 1958], Блек [Bleck, 1966], Бендикс [Bendix, 1964], Валерстейн [Wallerstein, 1974-1989], Дора [Dore, 1973], Гамильтон [Hamilton, 1994], Турен [Tourine, 1974], Белл [Bell, 1974], Бек и Уильямс [Beck and Willms, 2000], Фукуяма [Fukuyama, 1992], Панов [Панов, 2010], Яковлев [Яковлев, 2013] и многие другие. При этом специальные исследования социокультурной модели модернизации еще не проведены и адекватная ей стратегия преобразования пока не выработана. Данная работа частично заполняет этот пробел. 


\section{Сущцость социокультурной стратегии модернизации}

Важнейшей задачей социокультурной методологии является определение содержательного ядра и движущих сил модернизации, ценностных ориентаций и мотивов поведения индивидов, предпосылок создания условий для распространения модернизационных стандартов, объективных критериев признания государства современным.

Применение социокультурной методологии позволяет дифференцировать, идентифицировать и типологизировать стратегии преобразования, выделить ее типы (инновационно-опережающий, инновационно-догоняющий и имитационно-подражательный), а также развернуть структуру модернизации, которая включает социализацию, заимствование и адаптацию.

Предложим наше понимание социокультурной политики модернизации. Это совокупность аналитических и инструментальных методов социокультурной методологии, образующих ядро и структуру интеллектуального капитала. Они позволяют научным способом выделить этапы и формы модернизации, ее движущие силы, коммуникативные каналы, обеспечивающие первенство человеческого фактора в государстве и придание процессам социокультурной направленности. Этот универсальный феномен создает модель модернизации, теоретическую платформу политики, образец правил и императив ее разработки, опору, которая является необходимым условием.

Под институционализацией понимается социально значимое функционирование институтов государства, направленное на создание условий, соответствующих современным стандартам жизни, общественного блага, обеспечивающих формирование общества с преобладающей ролью средних слоев. Институционализация предполагает следующие составляющие:

1. Опора на специально разработанную научно-теоретическую модель модернизации.

2. Формирование программ и проектов с указанием конкретных этапов, фаз и сроков проведения преобразований.

3. Опора на собственные ресурсы страны, прежде всего на способности и возможности индивидов, их включение в процессы модернизации.

4. Создание условий для формирования национального интеллектуального капитала, новых технологий и сфер производства, занятости населения.

5. Заимствование положительного опыта модернизации различных стран мира, отбор наиболее подходящих форм, способов внедрения нововведений и осуществления реформ.

6. Проведение политики методами социализации, инкультурации общества и индивидов.

7. Обеспечение первенства человеческого фактора и человеческого потенциала в государстве и подчинение процессов социальному благополучию граждан.

8. Приход к власти политиков при наличии реальной политической модели, планов и проектов, внедрение практики ответственности политиков перед обществом на такой основе.

9. Формирование нового интеллектуального сообщества и повышение его экспертной роли; внедрение принципов устойчивого и контролируемого развития, меритократии и технократии.

10. Сокращение дистанции в развитии между развитыми и развивающимися обществами, трансформация имитационно-подражательной модели модернизации в инновационную (что прежде всего актуально для постсоветских обществ). 
Эти требования являются опорой институциональной стратегии политики модернизации. Без наличия соответствующего интеллектуального капитала она превратится в фальшивую и лицемерную демагогию корыстных политиков.

Преимущество социокультурной методологии состоит в том, что здесь человек и его социальные интересы имеют первостепенное значение. Поэтому социализация рассматривается не в контексте повседневной жизни, т. е. как первичная и вторичная социализация индивида, и не как процесс создания исключительно государством необходимых социальных условий, поскольку это чревато воспроизводством социально пассивных индивидов. Доказательством того, что такая опасность существует, являются провалы в политике построения «государства всеобщего благосостояния» США и в некоторых странах Востока. Для нас принципиальными являются самоактуализация человека, его способностей, а также переход общества на более высокий уровень развития. В этом суть социокультурной (а не просто социальной) природы человека, от развития которой зависит будущее государства.

Социализирующая функция модернизации играет стратегически важную роль для осуществления социокультурной политики. Это деятельность органов государственной власти, направленная на изменение, поддержание и развитие общества в соответствии с современными стандартами образа, качества, стиля и уровня жизни путем придания им императивно-правового значения. Она включает систему нововведений, стандарты политической и правовой культуры, социальные изменения, внедрение социальных норм, социальной инициативы, социальной помощи, социального порядка и т. п., которые выступают как предпосылки качественных изменений.

Социализация создает запускающие механизмы социально координирующих мотивационных ориентиров адаптации традиционного человека к современным процессам, формирует поле жизнедеятельности, каналы входа социокультурных ценностей в ядро центральной зоны социокультурных ценностей.

\section{Структура социокультурной модели модернизации}

Социокультурная модель модернизации опирается на такой механизм, как реформы, реализуемые путем преобразований, модификации, совершенствование, нововведения, реконструкции и т. д. Весь этот спектр изменений предполагает реализацию таких составных частей модернизации, как социализация, заимствование и адаптация, без чего модернизация невозможна. При этом необходимо знать специфику и структуру каждого из этих механизмов для понимания того, в каких случаях модернизация приобретает инновационно-опережающий, инновационно-догоняющий или имитационноподражательный вектор и следует соответствующей стратегии. Расшифровка механизмов модернизации позволит раскрыть секрет ее социокультурной направленности.

Рассмотрим каждую из структурных составляющих.

Социализация - процесс освоения обществом и индивидами новой культуры, нового социокультурного порядка, что предполагает внедрение новых правил и расширение возможностей человека в соответствии с современными стандартами жизни. Без социализации общество не может трансформироваться из традиционного в современное, поскольку данный феномен определяет непосредственную связь и отношения индивидов, групп и социума с социокультурным пространством. Социализация включает такие процессы, как обучение, освоение, развитие, мобилизация и актуализация индивидов, приобретение нового опыта, концентрация усилий, стимулирование, прогресс, совершенствование и т. д. Поэтому социокультурный вектор модернизации начинает 
формироваться именно с «запуска» данного феномена на основе конкретных концепций, планов, программ, реализуемых политикой социализации общества.

Заимствование также требует особого внимания в силу сложных и неординарных свойств и структуры.

Можно выделить несколько форм заимствования: а) приобретение нового опыта от других обществ; б) повторение положительного опыта своего общества; в) перенимание инноваций и их трансформация с учетом интересов конкретного общества (частичное заимствование); г) подражание и создание видимости современности и т. д. Все это необходимо для проведения сравнительного анализа модернизации и социокультурной модели, определения степени и форм заимствования, выявления типа стратегии преобразований - инновационно-опережающей, инновационно-догоняющей или имитационно-подражательной.

Например, такие формы заимствования, как приобретение нового и перенимание положительного опыта других обществ, а также перенос и трансформация инноваций (частичное заимствование с учетом специфики конкретного социума), могут способствовать реализации инновационно-опережающего курса модернизации.

Особого внимания требует процесс повторения прошлого опыта, который может проявляться в двух основных формах: в социально значимом и иррационально мифологическом, в зависимости от социализации и политической культуры общества, с одной стороны, и объема ресурсов интеллектуального капитала государства - с другой. Если в обществе делается акцент на повторении и воспроизводстве положительного опыта прошлого, к примеру, практики первенства интеллектуального капитала или человеческого фактора, социально ориентированной государственной политики, которые меняются и совершенствуются с учетом современных требований, то такое повторение прошлого опыта имеет позитивный и социально значимый характер. Оно обеспечивает реализацию инновационно опережающего вектора модернизации, так как традиционность здесь опирается на прочный фундамент накопленного в обществе положительного опыта, который в условиях современности обновляется и обогащается новациями, способствуя движению в социокультурном направлении. Образуется дихотомия «традиционное - современное», содержательная основа которой исключает консерватизм, догматизм и радикализм. В таком случае общество в основном опирается на собственный интеллектуальный капитал и ресурсы модернизации и прибегает лишь к частичному заимствованию образцов модернизации извне. Подобный курс модернизации могут проводить государства с богатым интеллектуальным капиталом и прочными традициями его накопления, создания и реализации (в основном это касается США, стран Западной Европы, Японии).

И наоборот, если процесс заимствования основывается на идеологемах и мифологемах прошлого, то модернизация приобретает иррациональную направленность и ее процессы отклоняются от социокультурного вектора развития. В дихотомии «традиционное - современное» доминируют консервативные ценности, формируется догоняюще-имитационная либо подражательная стратегия модернизации, отбрасывающая общество назад и приводящая к отсталости и зависимости государства от развитых стран мира.

Адаптация также требует особого внимания, так как модернизация является постоянно движущим феноменом изменения, развития и совершенствования общества. Поэтому адаптация - это процесс реформ, направленных на постоянное развитие и совершенствование социума. Адаптация непосредственно связана с социализацией, их базисом является интеллектуальный капитал, так как без него нет модернизации обще- 
ства. Отсюда первичность интеллектуального капитала и человеческого фактора в процессах модернизации: именно индивид разрабатывает и реализует образцы модернизации. В связи с этим социализацию следует считать первичным звеном в структуре модернизации, а адаптацию - вторичным, они находятся в прямой зависимости между собой.

Можно выделить следующие функции адаптации: внедрение новых образцов, реализация планов и проектов, изменение и преобразование процессов, объектов, общества и т. д. При этом следует отметить, что адаптация реализуется в трех направлениях: 1) на уровне общества, включая процесс внедрения новой роли и статуса граждан, новых социокультурных традиций и обычаев либо процесс постоянного поддержания функции гражданственности, повышения человеческого фактора и человеческого капитала в государстве; 2) на уровне различных институтов: изменения функционирования либо совершенствования существующих властных и социально значимых учреждений и организаций; 3) в социокультурных процессах - внедрение новых либо постоянное обновление старых правил социального взаимодействия государства и общества, защиты окружающей среды и т. д.

Эти составляющие адаптации способствуют реализации инновационно-опережающей стратегии модернизации, и если какая-то часть игнорируется, то и процесс модернизации отклоняется от социокультурного вектора, модернизация приобретает инновационно-догоняющий или имитационно-подражательный характер - в зависимости от степени искажения ее законов.

Нарушение процессов социализации приводит к искажению процессов адаптации. Имеется в виду первенство человеческого фактора при создании общества современного типа, которое часто подменяются мифологическими ценностями. Ставка на конкурентоспособность страны и профессионализм, а не на трансформацию индивида в современного гражданина, приводит к государствоцентричной политике страны и к реализации инновационно-догоняющей стратегии.

Вышесказанное подтверждает опыт ряда стран (например, Тайвань, КНР, Южная Корея и т. д.), которые имеют передовые показатели, обладают инновационной технологией, и при этом для них характерна догоняющая, а не инновационно-опережающая стратегия модернизации.

В современных условиях важно наличие не столько стандартов модернизации, сколько конкурентоспособного интеллектуального капитала, его богатого арсенала. Техника и технологии постоянно совершенствуются, что требует не столько материальных вложений, сколько интеллектуального капитала. Другое дело, сможет ли такой вектор трансформироваться и стать инновационным. Это зависит от темпов, объема и качества интеллектуального капитала страны и, самое главное, от способности и стремления общества. Иных рецептов развития стран, оторванных от человеческого капитала, модернизация не имеет.

\section{Первенство человеческого и интеллектуального капитала в социокультурной модели модернизации}

Модернизация как процесс массового распространения и установления нововведений, разработки и создания новых технологий, стремления к безграничному совершенствованию условий жизни человека и общества основывается на первенстве человеческого фактора и интеллектуального капитала. Они выступают как движущие механизмы модернизации и определяют ее стратегию. 
Стремление к совершенствованию условий жизни является столь же естественной потребностью человека, как и другие социально значимые запросы. Оно проявляется почти с самого рождения индивида, сопровождает его в течение жизни, служит мотивом поведения и стимулом развития способностей. Именно такие потребности образуют коммуникативные каналы человека с внешним миром и задают процессы преобразований, а, следовательно, и модернизации. Поэтому модернизация и социальные запросы человека взаимосвязаны и неразделимы. Первичность человеческого фактора и человеческого потенциала, совершенствование условий жизни, изменение общества к лучшему - базис социокультурной модели модернизации.

Отклонение от социокультурного вектора приводит к искажению модернизационных процессов в двух основных формах:

1) капиталоцентрической, когда вверх берет экономическая выгода, а первичность человеческого фактора подменяется первичностью законов экономической зависимости человека от прибыльно-экономической политики государства;

2) патерналистско-авторитарной - основанной на стремлениях государства к созданию «небесного рая на земле» (коммунизм), когда коллективные цели, ресурсы общества и социальные интересы граждан подчиняются планово-экономической политике и государствоцентричному вектору модернизации.

Первая форма модернизации, отклоняющаяся от социокультурной модели, имела место в странах Запада в середине XIX века; вторая - в Советском Союзе в $\mathrm{XX}$ столетии. Западное общество сумело преодолеть негативную форму. Постсоветское общество пока демонстрирует неопределенность в отношении содержания изменений переходного периода, поскольку не создана институциональная модель социокультурной модернизационной политики.

Но вместе с тем потенциальные возможности таких сил зависят исключительно от общества, от ресурсов знаний, профессионализма, способностей к преобразованию и изменению к лучшему и т. п. Поэтому в государстве, в котором первичны человеческий фактор и человеческий потенциал, создаются условия поддержания и реализации инновационно-опережающей стратегии модернизации, что обеспечивает лидирующие позиции страны в информационную эру. И, напротив, если государство не ценит человеческий капитал и игнорирует социализирующие механизмы модернизации, оно ставит себя в подчиненное положение относительно более развитых стран, обрекает себя на отсталость и зависимость.

\section{Критерии оценки современного государства}

Важнейшей задачей методологии социокультурных исследований является не только установление содержательного ядра и структуры модернизации, определение той или иной стратегии, но и выявление предпосылок распространения модернизационных стандартов на глобальном уровне, критериев оценки современных государств, а также наделение государств статусом модернизированных.

Известно, что традиционные представления о правилах участия государств в мировых глобализационных процессах устарели. Принцип превосходства социумов, имеющих удобное геополитическое положение и значительные запасы природных ресурсов, трансформировался. Это обусловлено тем, что продукция, созданная интеллектуальным трудом, т. е. субституты, в результате новых открытий заменяющие природные ресурсы, играет огромную роль в мировых экономических процессах. Главенство способностей государств, предоставляющих нововведения, изобретения, определяет конкурентоспособность, производственную способность и авторитет 
страны, уровень ее развития, отсталость либо современность. Правила игры на мировой экономической арене и лидерства стран подчиняются принципу «Страна может производить лучшую продукцию и предлагать продукцию, максимально доступную для преобладающей части населения стран мира». Заметим, что здесь важна не только прибыль, а ее перераспределение в интересах общества на социальные запросы и цели. В противном случае модернизация приобретает не опережающий, а догоняющий характер.

При оценке современных глобализационных процессов важно учитывать не только экономические показатели государств, но и социокультурный вектор экономики - максимизацию социальной пользы для общества как специфики современной экономической политики.

Выделим критерии значимости социокультурного вектора интеллектуального капитала модернизационной политики на внутригосударственном уровне: привязка политики к интересам и запросам общества, направленность на поддержание и постоянное совершенствование условий жизни индивидов, приумножение социальных благ и новых достижений; политические процессы и запросы граждан зависят не от политиков, а от степени влияния и масштабов применения интеллектуального капитала в различных сферах жизни общества; политика закладывает фундамент профессионального и рационального управления государством. Тезисы «вся власть специалистам» и «здоровая и образованная нация» [Белл, 1999] подчиняются принципу «устойчивое и контролируемое развитие». Устойчивость обеспечивается динамикой развития социальной, экономической, политической, культурной, правовой сфер интеллектуального капитала, созданием теоретической платформы соответствующих институтов и процессов. Контролируемость означает не контроль со стороны политиков, а анализ качества и уровня жизни, измеряемых специальными индексами, разработанными экспертным сообществом, что исключает фальсификацию и искаженность процессов, критериев оценки эффективности политики и лидеров страны. Практика показывает, что государства, осознавшие его социокультурное значение, осуществившие замену старого порядка новыми правилами жизни, социально-технологическую организацию общества, занимают лидирующие позиции. Это вызов самой модернизации, а не «каприз» какой-то страны, и не считаться с ней недопустимо и неприемлемо прежде всего для постсоветских обществ.

\section{Выводы}

Исходя из вышеизложенного, сделаем следующие выводы:

1. Модернизация - это информационно-коммуникативный феномен, дающий толчок социокультурным изменениям. Она опирается на способность общества к социокультурным преобразованиям, созданию современного государства, стремлению перейти к более совершенным формам.

2. Структура социокультурной модели модернизации включает социализацию, заимствование и адаптацию. Социализация связана с инкультурацией, реформами, освоением социумом новых практик и опыта жизнедеятельности, социально значимых традиций, обычаев, ценностей, с политической культурой участия; заимствование - это воспроизводство положительного опыта прошлого, перенимание достижений других стран, проведение реформ, зависимость процессов от инкультурации и социализации; адаптация - внедрение, реализация, применение новшеств.

Эти структурные составляющие взаимосвязаны и выполняют роль коммуникативных каналов модели, определяют тип стратегии преобразований (инновационно- 
опережающей, инновационно-догоняющей или иммитационно-подражательной).

3. Модернизация осуществляется на основе специально разработанного интеллектуального капитала. Цель - опора политики на движущие факторы модернизации, придание политике социокультурной направленности, подчинение всех процессов первенству человеческого фактора и социальным интересам граждан страны.

5. Устойчивое и контролируемое развитие опирается на показатели социокультурных индексов, которые оцениваются экспертным сообществом, что обеспечивает принцип меритократии и технократии.

6. Управление внутриполитическими и межгосударственными процессами доверяется высокопрофессиональным политикам, реализующим научно разработанную социокультурную политику, отвечающим за результаты самой модернизации.

7. В контексте мировой политики модернизация рассматривается как глобальный процесс социального партнерства с приматом человеческого фактора и человеческого капитала, что определяет ее социокультурный вектор.

8. Мировой статус государства определяют не экономические показатели, а положение простых членов общества страны, первенство человеческого капитала и статус интеллектуального капитал.

9. На смену политике доминирования и двойных стандартов государств приходит политика обеспечения баланса сил и мировой безопасности, минимизирующая механизмы принуждения и давления.

Важно, чтобы экономические факторы, принципы конкуренции, соперничества, стремление быть постмодернистским государством не поглощали человеческий фактор как внутри страны, так и в глобальных процессах. Защитным механизмом от таких угроз и вызовов может стать научно разработанная инновационно-опережающая стратегия политики модернизации, опирающаяся на социокультурную методологию и теоретические исследования.

\section{Литература}

1. Almond G. and Powell G.B. Comparative Politics: A Developmental Approach. Boston: Little Brown, 1966.

2. Apter D. Rethinking Development: Modernization, Dependency and Postmodern Politics. - London: Sage, 1987.

3. Aron R. Progress and disillusion: the Dialectics of Modern Society. - New York: Mentor Books, 1969.

4. Baker $K$. Inventing the French Revolution. - Cambridge: Cambridge University Press, 1990.

5. Beck U., Diddens A. and Lash S. Reflexive Modernization: Politics, Tradition and Aestetics in the Modern Social Order. - Stanford, California: Stanford University Press, 1994.

6. Белл Д. Грядущее постиндустриальное общество. Опыт социального прогнозирования. - М.: Academia, 1999.

7. Dinner E. The Satisfaction with Life Scale // Journal of Personality Assessment. 1985. - V. 49, № 1.

8. Eisenstadt S.N. European Civilization in Comparative Perspective. - Oslo: Norwegian University Press, 1987.

9. Tiryakian E. Modernization; Exhumetur in Pace (Rethinking Macrosociology in the 1990s) // International Sociology. - 1991. - № 6 (2). - P. 165-180 1991.

10. Zapf W. Die Modernisierung Moderner Gesellschaften. - Frankfurt: Campus Verlag, 
11. Transforming our World: The 2030 Agenda for Sustainable Development. United Nations, 2015. - Режим доступа: https://sustainabledevelopment.un.org/

12. Панов А. Революция Сёва. Модернизация Японии в послевоенный период. М.: Восток-Запад, 2010.

13. Хобсбаум Э. Век революции 1789-1848. - Ростов н/Д: Феникс, 1999.

14. Хобсбаум Э. Век капитала 1848-1875. - Ростов н/Д: Феникс, 1999.

15. Цели устойчивого развития. http://www.un.org/sustainabledevelopment/ru/ (дата обращения 24.06.2017).

16. Яковлев А. Очерки модернизации стран Востока и Запада в XIX-XX веках. М.: Восточный университет, 2006.

17. Концепция модернизации в зарубежной социально-политической теории 1950-1960 гг. - М.: ИНИОН РАН, 2012.

18. Ростоу У.У. Политика и стадии роста. - М.: Прогресс, 1973.

19. Форрестер Д. Мировая динамика. - М.: АСТ, 2006.

20. Хиршман А. Риторика реакции: извращение, тщетность, опасность. - М.: ВШЭ, 2010 .

\section{References}

1. Almond G. and Powell G.B. Comparative Politics: A Developmental Approach. Boston: Little Brown, 1966. - P. 213-332.

2. Apter D. Rethinking Development: Modernization, Dependency and Postmodern Politics. - London: Sage, 1987.

3. Aron R. Progress and disillusion: the Dialectics of Modern Society. - New York: Mentor Books, 1969.

4. Baker K. Inventing the French Revolution. - Cambridge: Cambridge University Press, 1990.

5. Beck U., Diddens A. and Lash S. Reflexive Modernization: Politics, Tradition and Aestetics in the Modern Social Order. - Stanford, California: Stanford University Press, 1994.

6. Bell D. The Coming of Post-industrial Society. A Venture Experience of Social Forecasting. - M.: Academia, 1999.

7. Dinner E. The Satisfaction with Life Scale // Journal of Personality Assessment. 1985. - V. 49, № 1.

8. Eisenstadt S.N. European Civilization in Comparative Perspective. - Oslo: Norwegian University Press, 1987.

9. Tiryakian E. Modernization; Exhumetur in Pace (Rethinking Macrosociology in the 1990s) // International Sociology. - 1991. - № 6 (2). - P. 165-180. 1991.

10. Zapf $W$. Die Modernisierung moderner Gesellschaften. - Frankfurt: Campus Verlag,

11. Transforming our World: The 2030 Agenda for Sustainable Development. United Nations, 2015. - Режим доступа: https://sustainabledevelopment.un.org/

12. Panov A. Sowing revolution. Modernization of Japan during the post-war period. M.: East-West, 2010.

13. Hobsbaum E. Century of revolution of 1789-1848. - Rostov n/D: Phoenix, 1999.

14. Hobsbaum E. Century of the capital of 1848-1875. - Rostov n/D: Phoenix, 1999.

15. Sustainable Development Goals.

16. Yakovlev A. Sketches of modernization of the countries of the East and West in the 19-20th centuries. - M.: East university, 2006.

17. The concept of modernization in the foreign socio-political theory of 1950-1960 Sb. translations. - M. Lane: INION of RAS, 2012. 
18. Rostou U.U. Politika and stages of growth. - M.: Progress, 1973.

19. Forester D. World dynamics. - M.: Nuclear heating plant, 2006.

20. Hirschman A. Rhetoric of reaction: perversion, futility, danger. - M.: HSE, 2010.

Поступила в редакиию 14 августа 2018 г.

UDC 301:37

DOI: $10.21779 / 2500-1930-2018-33-4-56-65$

\section{Sociocultural methodology in the development of modernization policy}

\section{M.R. Demetradze}

Russian State University for the Humanities; Russia; Moscow, Miusskaya Square 6, bldg. 1; demetradze1959@mail.ru

The given article undertakes an attempt to present sociocultural methodology of modernization policy in which strategic function is performed by such categories as socialization, loan and adaptation. Specifics and structure of each of these mechanisms, enables to define in what cases modernization gets innovative advancing, the innovative catching-up or imitating and imitative vector. The purpose of sociocultural methodology embraces the following constituents: support on specially developed scientific-theoretical modernization model, policy bound to the interests and inquiries of society, its orientation on maintenance and constant improvement of individuals' living conditions. It lays the foundation for professional and rational government management. The thesis "all power to experts", "healthy and educated nation" submit to the principle "sustainable and controlled development". Primacy of a human factor and human potential, improvement of living conditions, social transformations to the best are the basis of sociocultural model of modernization.

Keywords: sociocultural methodology, sociocultural modernization, policy, socialization, loan, adaptation, human factor, intellectual capital, sustainable and controlled development.

Received 14 August, 2018 